\title{
Perfil bacteriológico das mãos e aparelhos celulares dos profissionais de saúde que trabalham e frequentam a Unidade de Terapia Intensiva de um Hospital
}

\section{Universitário}

\author{
Bacteriological profile of the hands and cell phones of health professionals who work and attend the \\ Intensive Care Unit of a University Hospital \\ Perfil bacteriológico de las manos y teléfonos celulares de los profesionales de la salud que laboran \\ y asisten a la Unidad de Cuidados Intensivos de un Hospital Universitario
}

\section{Resumo}

As Infecções Relacionadas à Assistência em Saúde são multifatoriais e ocorrem devido a fatores que poderiam ser evitados como, a lavagem inadequada das mãos e o manuseio de materiais. O objetivo deste trabalho foi conhecer o perfil bacteriológico das mãos e telefones celulares da equipe multiprofissional e dos profissionais que frequentam a Unidade de Terapia Intensiva do HU-UNIVASF. Foram analisadas as mãos e aparelhos celulares da equipe multidisciplinar da UTI. A pesquisa foi separada em 3 grupos: grupo 1: mão dominante e/ou aparelho celular de profissionais que compõem a equipe multiprofissional que chegam ao setor para o plantão; grupo 2: mão dominante e/ou aparelho celular de profissionais que compõem a equipe multiprofissional que deixam o setor ao final do plantão e o grupo 3: mão dominante e/ou aparelho celular de profissionais que entram na UTI para realizar alguma atividade. Após a passagem do swab, nas mãos e nos aparelhos celulares, as amostras foram transportadas para o Laboratório onde foi realizada a análise microbiológica. Pode-se observar, nas mãos e nos aparelhos celulares, a incidência das principais bactérias causadoras de infecções hospitalares, são elas: Acinetobacter baumannii, Pseudomonas aeruginosa, Klebsiella pneumoniae, Enterococcus spp. e Staphylococcus aureus. Em relação ao perfil bacteriológico, observa-se que as bactérias isoladas apresentam diferentes perfis de resistência, entre eles, a presença de bactérias multirresistentes. Os profissionais que atuam na UTI do HU-UNIVASF e aqueles que entram para realizar atividades possuem em suas mãos e aparelhos celulares bactérias multirresistentes causadoras de infecções hospitalares que poderão causar infecções cruzadas.

Palavras-chave: Infecção hospitalar; Unidades de Terapia Intensiva; Desinfecção das mãos; Telefones celulares. 


\begin{abstract}
Health Care Related Infections are multifactorial and occur due to factors that could be avoided, such as inadequate hand washing and material handling. The objective of this study was to know the bacteriological profile of the hands and cell phones of the multidisciplinary team and professionals who attend the Intensive Care Unit of the HUUNIVASF. The hands and cell phones of the multidisciplinary ICU team were analyzed. The research was divided into 3 groups: group 1: dominant hand and/or cell phone of professionals who make up the multidisciplinary team who arrive at the sector for the duty; group 2: dominant hand and/or cell phone of professionals who make up the multidisciplinary team who leave the sector at the end of their shift and group 3: dominant hand and/or cell phone of professionals who enter the ICU to perform some activity. After passing the swab, in the hands and in cell phones, the samples were transported to the Laboratory where the microbiological analysis was performed. In the hands and cell devices, the incidence of the main bacteria causing infections can be observed, they are: Acinetobacter baumannii, Pseudomonas aeruginosa, Klebsiella pneumoniae, Enterococcus spp. and Staphylococcus aureus. Regarding the bacteriological profile, it is observed that the isolated bacteria have different resistance profiles, including the presence of multiresistant bacteria. Professionals working in the ICU of the HU-UNIVASF and those who come in to carry out activities have in their hands and cell devices multiresistant bacteria that cause hospital infections that may cause cross-infection.
\end{abstract}

Keywords: Cross infection; Intensive Care Units; Hand disinfection; Cell phone.

\title{
Resumen
}

Las infecciones relacionadas con la atención médica son multifactoriales y ocurren debido a factores que podrían evitarse, como el lavado de manos y el manejo de materiales inadecuados. El objetivo de este estudio fue conocer el perfil bacteriológico de las manos y teléfonos celulares del equipo multidisciplinario y de los profesionales que asisten a la Unidad de Cuidados Intensivos de la HU-UNIVASF. Se analizaron las manos y teléfonos móviles del equipo multidisciplinario de UCI. La investigación se dividió en 3 grupos: grupo 1: mano dominante y / o celular de los profesionales que integran el equipo multidisciplinario que llega al sector para el deber; grupo 2: mano dominante y / o celular de los profesionales que abandonan el sector al finalizar su turno y grupo 3: mano dominante y / o celular de los profesionales que ingresan a la UCI para realizar alguna actividad. Luego de pasar el hisopo, en las manos y en los celulares, las muestras fueron transportadas al Laboratorio donde se realizó el análisis microbiológico. En las manos y celulares se puede observar la incidencia de las principales bacterias, son: Acinetobacter baumannii, Pseudomonas aeruginosa, Klebsiella pneumoniae, Enterococcus spp. y Staphylococcus aureus. En cuanto al perfil bacteriológico, se observa que las bacterias aisladas tienen diferentes perfiles de resistencia, incluida la presencia de bacterias multirresistentes. Los profesionales que laboran en la UCI de la HU-UNIVASF y los que acuden a realizar actividades tienen en sus manos y dispositivos celulares bacterias multirresistentes que provocan infecciones que pueden ocasionar infecciones cruzadas.

Palabras clave: Infección hospitalaria; Unidades de Cuidados Intensivos; Desinfección de las manos; Teléfono celular.

\section{Introdução}

O Ministério da Saúde e a Agência Nacional de Vigilância Sanitária (ANVISA) substituíram o termo Infecções Hospitalares (IH) por Infecções Relacionadas à Assistência em Saúde (IRAS). As IRAS são infecções causadas por diversos patógenos e ocorrem durante a assistência à saúde, abrangendo atendimentos ambulatoriais hospitalares ou domiciliares e procedimentos assistenciais diagnósticos ou terapêuticos (Centers for Disease Control and Prevention, 2019). As infecções aumentam o tempo de internação e a morbimortalidade nos serviços de saúde, elevando consequentemente os custos na assistência ao paciente (Agência Nacional de Vigilância Sanitária, 2017).

De acordo com a Organização Mundial de Saúde (OMS) (2016) em países de média e baixa renda, as infecções relacionadas à assistência a saúde ocorrem mais em pacientes internados em Unidades de Terapia Intensiva (UTI). Estimativas europeias mostram que mais de 4 milhões de pacientes são afetados anualmente por infecções hospitalares, causando um impacto econômico de aproximadamente 7 bilhões de euros. Nos Estados Unidos da América, foi estimado que cerca de 1,7 milhões de pacientes são afetados por infecções hospitalares, representando uma prevalência de 4,5\% e custos médios anuais de \$ 35,7 a US \$ 45 bilhões. Em continentes como América Latina, Ásia e África a taxa de mortalidade para infecções do trato urinário foi de 18,5\%, para infecções associadas à corrente sanguínea foi de 23,6\% e 29,3\% para pneumonia associada a ventilação mecânica (World Health Organization, 2016).

As IRAS são multifatoriais e em grande parte das vezes sua ocorrência pode se dar por fatores que poderiam ser 
evitados como: a lavagem inadequada das mãos, manuseio de matérias, realização de procedimentos desrespeitando as técnicas assépticas, dentre outras (Portela et al., 2020). O controle das IRAS deve ser resultado de um trabalho por parte de toda a equipe de saúde (Mourão \& Chagas, 2020).

Realizar a lavagem adequada das mãos antes do contato com o paciente ou de qualquer ação que resulte em transmissão de bactérias reduz o risco de contaminação cruzada. A higienização das mãos minimiza microrganismos adquiridos durante as atividades diárias relacionadas à assistência ao paciente. De acordo com a OMS no Guidelines on Hand Hygiene in Health Care, vários estudos mostram a diminuição da colonização de pacientes e da incidência de isolados bacterianos multirresistentes após a implementação de cuidados relacionados a higiene adequada das mãos (World Health Organization, 2016).

As mãos dos profissionais de saúde são um importante vínculo de infecção cruzada. A técnica adequada de lavagem das mãos é simples e capaz de reduzir a disseminação das infecções nos serviços de saúde (Araújo et. al., 2016). Devido a falhas em técnicas assépticas, em limpezas de superfícies e a falta de adesão à lavagem das mãos é frequente a ocorrência de surtos infecciosos em setores como a Unidade de Terapia Intensiva (Paula et al., 2017).

Grande parte das IRAS se dá em pacientes internados em UTI em estados críticos. Os pacientes que se encontram na UTI, geralmente, estão debilitados e com uma maior dependência de cuidados do que aqueles que estão em outras unidades hospitalares. Dentro do cuidado ao paciente crítico, a utilização de procedimentos invasivos é necessária e a prevalência de infecções hospitalares relacionadas a esses dispositivos é elevada, sendo os principais relacionados às IRAS: intubação endotraqueal e utilização de ventilação mecânica, cateterização urinária e os cateteres intravascular (Inoue et al., 2010; Sousa et al., 2017).

Devido ao fato de que equipamentos e superfícies inanimados nas UTI's são contaminados por bactérias, a equipe multiprofissional deve estar ciente do risco de contaminação cruzada pelos microrganismos patogênicos presentes nestas superfícies para, deste modo, adotar medidas apropriadas no controle de infecção (Dresch et al., 2018).

Cardoso e Reis (2016), evidenciaram um elevado percentual de contaminação em superfícies da UTI de um Hospital Universitário de Goiás, com destaque para as bactérias gram-negativas: Pseudomanas aeruginosa, Klebisiella pneumoniae, Enterobacter agglomerans e Enterobacter aerogenes, que são capazes de causar infecções em sítios cirúrgicos, trato respiratório, trato urinário e corrente sanguínea.

Em uma pesquisa realizada por Menezes et al. (2016), foi avaliado a microbiota presente nas mãos dos profissionais de saúde do Centro Cirúrgico, onde foram encontradas as bactérias gram-positivas: Staphylococcus aureus, Staphylococcus coagulase negativa, Bacillus spp., Corinebacterium, Streptococcus do grupo viridans e bactérias gram-negativas como Klebsiella, Moraxella e Acinetobacter. Em outra pesquisa realizada por Caveião et al. (2014), foram coletados swabs de vigilância em aparelhos celulares de profissionais de um Hospital em Curitiba, onde foram identificadas bactérias como Staphylococcus coagulase negativa, Streptococcus do grupo viridans e bacilos gram negativos.

Em superfícies e equipamentos, assim como nas mãos dos profissionais de saúde podem ser encontradas bactérias multirresistentes. Os microrganismos estão avançando no que diz respeito a capacidade de resistência. Conhecer as bactérias multirresistentes e os mecanismos de resistência permite uma terapia medicamentosa racional (Fracarolli et al., 2017; Valdés, 2017).

Dentre as bactérias gram-positivas resistentes causadoras de infecções relacionadas à assistência a saúde, destacam-se Enterococcus resistentes à vancomicina (VRE), Staphylococcus aureus resistentes à meticilina (MRSA) e Staphylococcus coagulase negativa (ECN) com sensibilidade reduzida e resistência à oxacilina e a cefalotina (Rosa et al., 2009; Hoecke, 2011).

Para as gram-negativas, Enterobacter resistentes a aminoglicosideos, cefalosporinas de terceira geração e fluorquilonas; Kleibsiella pneumoniae produtoras e Betalactamase de espectro estendido e carbapenemases; Escherichia coli 
produtoras de Betalactamase de espectro estendido e resistentes a flourquinolonas; Pseudomonas aeruginosa e Acinetobacter baumannii resistentes a carbapenêmicos, merecem destaque entre essas bactérias (Peirano et al, 2009).

Percebe-se que ações como lavagem adequada das mãos, desinfecção de equipamentos, uso de equipamentos de proteção individual são consideradas medidas de prevenção, que é a principal arma contra as infecções hospitalares (Cunha, 2017). Ante o exposto, esta pesquisa objetivou conhecer o perfil bacteriológico das mãos e telefones celulares da equipe multiprofissional e dos profissionais que frequentam a unidade de terapia intensiva do HU-UNIVASF.

\section{Metodologia}

O experimento foi realizado nos meses de agosto de 2018 a dezembro de 2018 na Unidade de Terapia Intensiva (UTI) do Hospital Universitário da Universidade Federal do Vale do São Francisco (HU-UNIVASF/EBSERH) em Petrolina, Pernambuco.

No presente estudo foi utilizada metodologia de natureza quantitativa (Pereira et al., 2018). Trata-se de um estudo transversal e descritivo desenvolvido com o intuito de determinar o papel das mãos e dos aparelhos celulares no ambiente hospitalar como reservatório de agentes etiológicos bacterianos associados às IRAS. Foram analisadas as mãos e aparelhos celulares dos profissionais de saúde e da equipe multidisciplinar da UTI.

A pesquisa foi dividida em três grupos: grupo 1: mão dominante e/ou aparelho celular de profissionais que compõem a equipe multiprofissional que chegam ao setor para o plantão; grupo 2: mão dominante e/ou aparelho celular de profissionais que compõem a equipe multiprofissional que deixam o setor ao final do plantão e o grupo 3: mão dominante e/ou aparelho celular de profissionais que entram na UTI para realizar alguma atividade. Em cada grupo foram amostradas 20 mãos de profissionais e 20 aparelhos celulares. As coletas foram realizadas após a concordância por meio do Termo de Consentimento Livre e Esclarecido - TCLE.

A metodologia utilizada foi segundo Santos et al. (2020) modificado, onde nas amostras das mãos, assim como nos aparelhos celulares foram analisadas duas regiões e superfícies, respectivamente, onde foi utilizado um molde de papel filtro de área de $4 \mathrm{~cm}^{2}$. Nas mãos, na primeira região, o molde foi colocado nas falanges, na parte anterior da mão, onde foi passado o swab estéril, embebidos em solução salina, girando o swab em seu próprio eixo. Na segunda região, os swabs foram passados ao redor e embaixo das unhas. Nos aparelhos celulares, a primeira superfície que foi amostrada foi a região do teclado do aparelho e a segunda foi a parte de trás do aparelho, na altura do teclado também.

Após a passagem do swab, nas mãos e nos aparelhos celulares, eles foram armazenados em tubo contendo $5 \mathrm{~mL}$ meio líquido BHI (Brain Heart Infusion). Em seguida, as amostras foram transportadas para o Laboratório de Análises Clínicas e Anatomia Patológica/ Setor Microbiologia do HU-UNIVASF (EBSERH), onde foi realizada a análise microbiológica.

No laboratório, os caldos BHI foram incubados a $37^{\circ} \mathrm{C}$ por 48 horas. Para o isolamento das bactérias, as amostras foram semeadas em Ágar Sangue (AS) e incubadas a $37^{\circ} \mathrm{C}$ por 24 horas. Após o período de incubação foi realizado a coloração de Gram e as provas bioquímicas para a identificação de cada espécie. Para identificação dos cocos gram-positivos foi realizada a prova de catalase. Quando a catalase foi positiva, foi realizado a prova de coagulase, e quando a catalase foi negativa, utilizou-se o Kit para Enterococcus, bacitracina e optoquina para identificar as espécies. Para a identificação de bacilos Gram negativos foram utilizados os kits para identificação de Enterobactérias e/ou de Não Fermentadores de glicose PROBAC®, conforme as instruções do fabricante.

As bactérias identificadas foram submetidas ao antibiograma pelo método de Ágar Difusão em Disco conforme as instruções CLSI (2018) e a escolha dos antimicrobianos realizada conforme o microrganismo isolado. Os resultados foram armazenados e analisados em uma planilha eletrônica de dados (Microsoft Excel® 2003).

A presente pesquisa foi condicionada ao cumprimento dos princípios éticos previstos nas diretrizes e normas 
regulamentadoras de pesquisa envolvendo seres humanos (Resolução $\mathrm{N}^{\circ}$ 466, de 12 de dezembro de 2012). O projeto foi submetido à apreciação do Comitê de Ética e Deontologia em Estudos e Pesquisas (CEDEP) da Universidade Federal do Vale do São Francisco - UNIVASF, com parecer de aprovação registrada sob nº 2.806.297 / CAEE nº 8885218.0.0000.5196.

\section{Resultados}

O total de bactérias encontradas, independente dos grupos analisados foi de 325, destas 62 (19\%) são consideradas possíveis bactérias causadoras de infecções hospitalares.

Em relação às bactérias isoladas das mãos da equipe multiprofissional que chega para receber o plantão (grupo 1), das 36 bactérias encontradas nas falanges da parte anterior da mão (região 01), oito são possíveis bactérias causadoras de infecções hospitalares. Das 31 bactérias encontradas ao redor e embaixo das unhas (região 02), dez são possíveis bactérias causadoras de infecções hospitalares. Nas mãos foram encontradas 67 bactérias, sendo 18 (27\%) possíveis bactérias causadoras de infecção hospitalar. Na Figura 1, pode-se observar a incidência de espécies bacterianas isoladas das mãos, da equipe multiprofissional que chega para receber o plantão.

Figura 1. Incidência de bactérias isoladas das mãos da equipe multiprofissional que chega para receber o plantão na UTI do HU-UNIVASF (EBSERH).

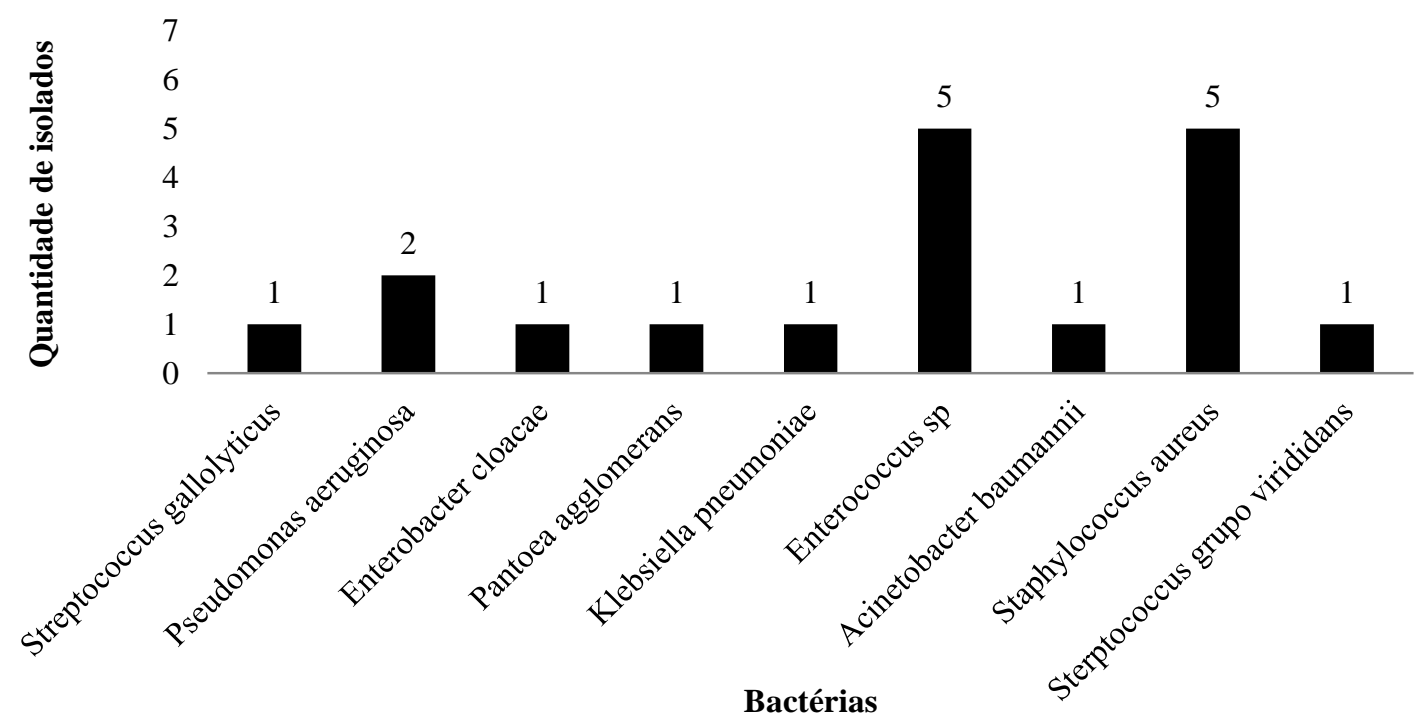

Fonte: Autores.

Quanto aos aparelhos celulares da equipe multiprofissional que chega para receber o plantão, das 26 bactérias encontradas na região do teclado do aparelho (região 01), cinco são possíveis bactérias causadoras de infecções hospitalares. Das 23 bactérias encontradas na parte posterior na altura do teclado (região 02), três são possíveis bactérias causadoras de infecção hospitalar. Nos aparelhos celulares foram encontradas um total de 49 bactérias, sendo 08 (16\%) possíveis bactérias causadoras de infecções hospitalares. Na Figura 2, pode-se observar a incidência de espécies bacterinas isoladas dos aparelhos celulares, da equipe multiprofissional que chega para receber o plantão. 
Figura 2. Incidência de bactérias isoladas nos aparelhos celulares da equipe multiprofissional que chega para receber o plantão na UTI do HU-UNIVASF (EBSERH).

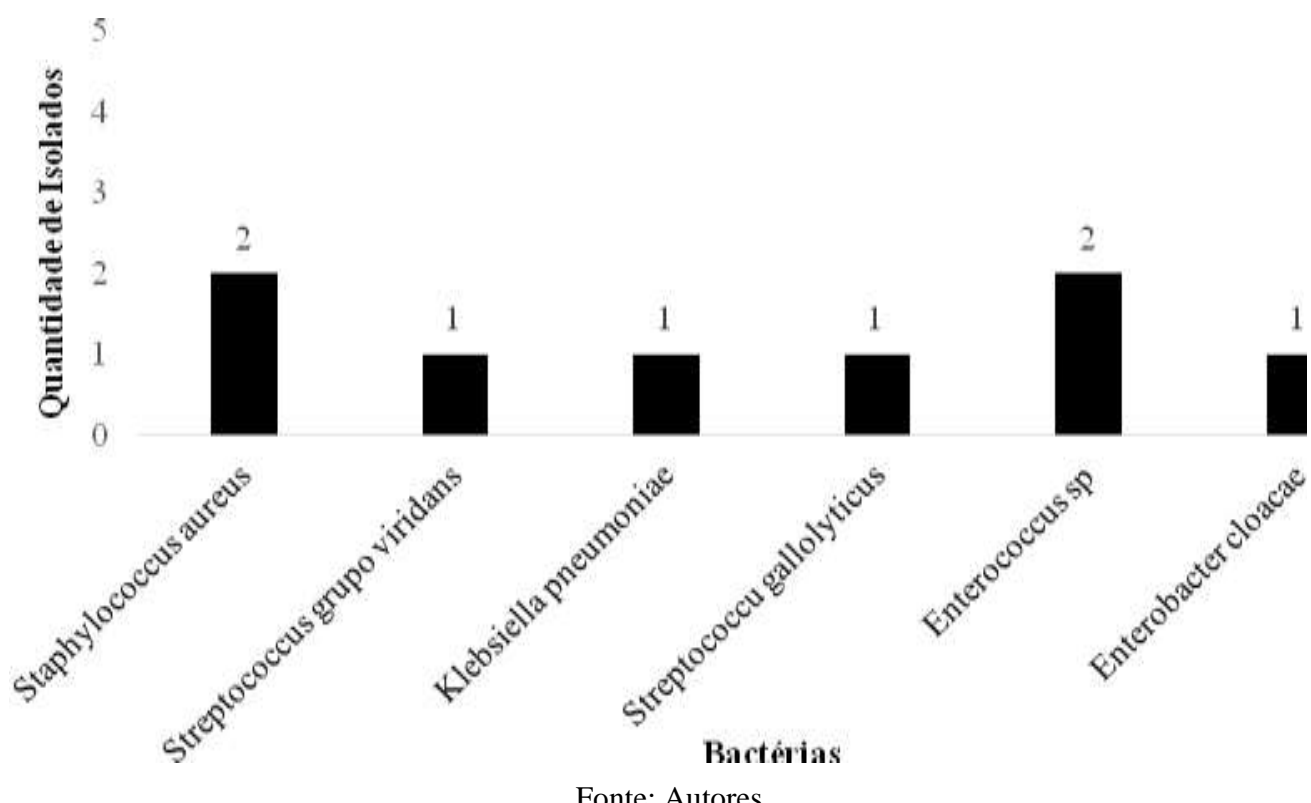

No grupo 22, profissionais que compõe a equipe multiprofissional da UTI e deixam o setor ao final do plantão, das 22 bactérias encontradas nas falanges da parte anterior da mão, duas são possíveis bactérias causadoras de infecções hospitalares. Das 24 bactérias encontradas ao redor e embaixo das unhas, cinco são possíveis bactérias causadoras de infecções hospitalares. Em relação aos aparelhos celulares, das 24 bactérias encontradas na região do teclado do aparelho, cinco são possíveis bactérias causadoras de infecções hospitalares. Das 16 bactérias encontradas na parte posterior na altura do teclado, duas são possíveis bactérias causadoras de infecções hospitalares. No total das mãos foram encontradas 46 bactérias sendo sete (15\%) possíveis causadoras de infecções hospitalares (Figura 3). No total dos aparelhos celulares foram encontradas 40 bactérias, sendo sete $(17,5 \%)$ possíveis causadoras de infecções hospitalares (Figura 4).

Figura 3. Incidência de bactérias isoladas das mãos da equipe multiprofissional da UTI do HU-UNIVASF (EBSERH) que deixam o setor ao final do plantão.

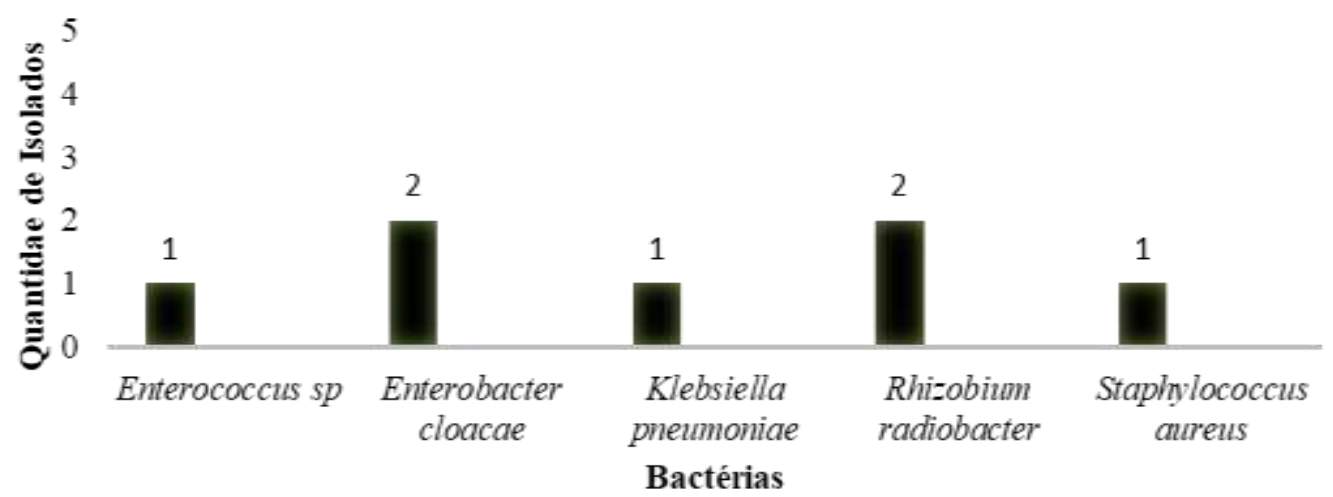

Fonte: Autores. 
Figura 4. Incidência de bactérias isoladas dos aparelhos celulares da equipe multiprofissional da UTI do HU-UNIVASF (EBSERH) que deixam o setor ao final do plantão.

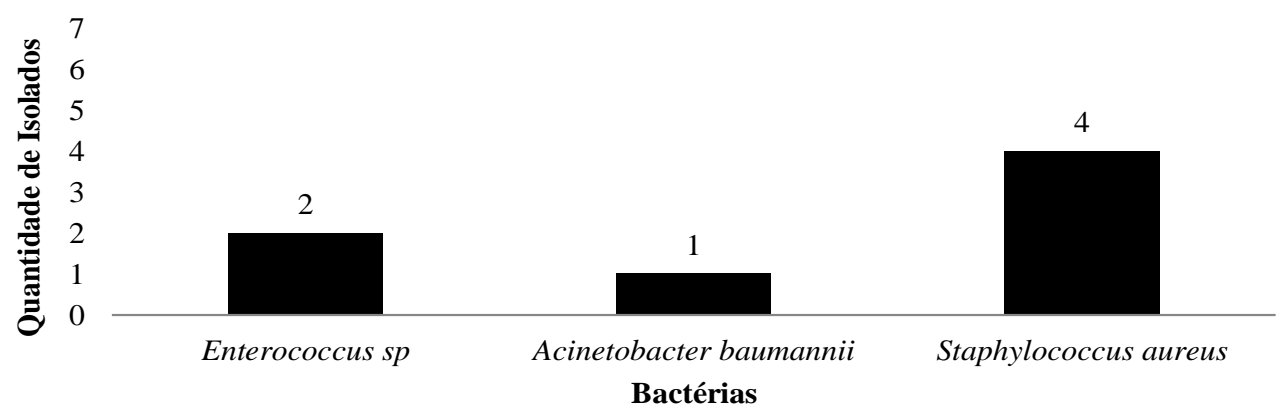

Fonte: Autores.

No que se refere as bactérias isoladas das mãos e aparelhos celulares dos profissionais que entram na UTI para realizar alguma atividade (grupo 3), das 35 bactérias encontradas nas falanges da parte anterior da mão, sete são possíveis bactérias causadoras de infecções hospitalares. Das 35 bactérias encontradas ao redor e embaixo das unhas, oito são possíveis bactérias causadoras de infecções hospitalares. Em relação aos aparelhos celulares das 23 bactérias encontradas na região do teclado do aparelho, duas são possíveis bactérias causadoras de infecções hospitalares. Das 30 bactérias encontradas na parte posterior na altura do teclado, cinco são possíveis bactérias causadoras de infecções hospitalares. No total das mãos foram encontradas 70 bactérias sendo 15 (21\%) possíveis causadoras de infecções hospitalares (Figura 5). No total dos celulares foram encontradas 53 bactérias sendo sete (13\%) possíveis causadoras de infecções hospitalares (Figura 6).

Figura 5. Incidência de bactérias isoladas das mãos de profissionais que entram na UTI do HU-UNIVASF (EBSERH) para realizar alguma atividade.

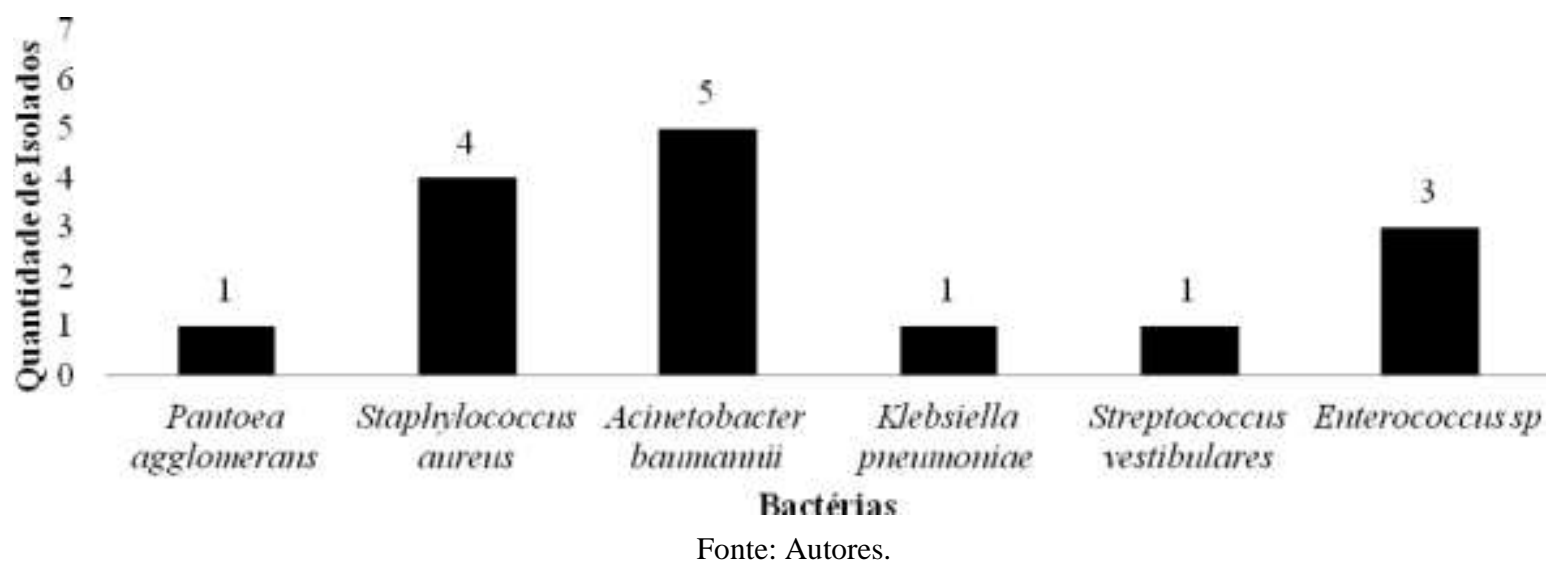


Figura 6. Incidência de bactérias isoladas nos aparelhos celulares dos profissionais que entram na UTI do HU-UNIVASF (EBSERH) para realizar alguma atividade.

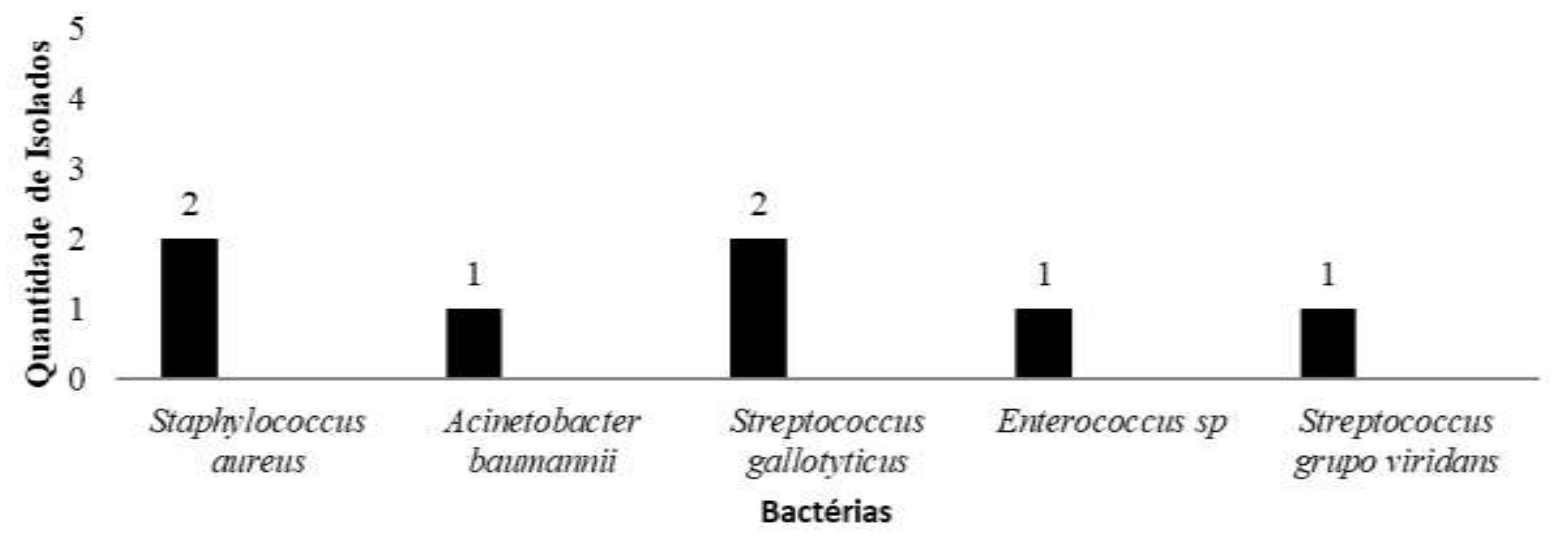

Fonte: Autores.

Dos três grupos analisados, o que mais apresentou bactérias causadoras de infecções hospitalares foi o grupo 01 (total de 26 bactérias), seguido do grupo 03 (total de 22 bactérias) e do grupo 02 (total de 14 bactérias). Diante destes resultados pode-se observar que o grupo que apresentou uma maior quantidade de possíveis bactérias causadoras de infecções hospitalares foi o que chega ao setor para receber o plantão, isso pode estar relacionado à falta do processo de lavagem das mãos pela equipe multiprofissional para entrar no setor e começar a realizar suas atividades rotineiras.

Independente dos grupos, o local onde foi encontrada a maior quantidade de bactérias patogênicas foi nas mãos, com um total de 40 bactérias. Nos aparelhos celulares foi encontrado um total de 22 bactérias. Em relação às mãos, independente do grupo, foram encontradas mais bactérias ao redor e embaixo das unhas, com um total de 23 bactérias patogênicas, isso pode ter relação com o tamanho das unhas das pessoas que participaram da pesquisa e com o processo de lavagem das mãos, que provavelmente está sendo realizado de forma incorreta. Nos aparelhos celulares a maior parte de bactérias causadoras de infecção hospitalar foi encontrada na região do teclado do aparelho, com um total de 12 bactérias.

Em relação ao perfil de sensibilidade e resistência das bactérias Gram-negativas (Tabela 01) encontradas nas mãos e telefones celulares dos profissionais, $25 \%$ dos Acinetobacter baumannii foram resistentes a sulfametoxazol + trimetoprima e $62 \%$ apresentaram resistência intermediaria ao ciprofloxacino. Para Enterobacter cloacae, 67\% foram resistentes a ceftriaxona e $100 \%$ resistentes a ampicilina + sulbactam. Para Klebsiella pneumoniae, $25 \%$ foram resistentes a meropenem e $100 \%$ resistentes a ampicilina. Enterobacter aerogenes, foram $100 \%$ resistentes a ampicilina e a ampicilina + sulbactam e os isolados de Pantoa agglomerans foram 50\% resistentes a ampicilina e a cefoxitina. Pseudomonas aeruginosa foram 100\% sensíveis aos antibióticos testados. 
Tabela 1. Perfil de sensibilidade e resistência das bactérias Gram-negativas encontradas nas mãos e aparelhos celulares de profissionais de saúde que trabalham e frequentam a UTI do HU-UNIVASF (EBSERH).

\begin{tabular}{|c|c|c|c|c|c|c|c|c|c|c|c|c|}
\hline \multirow[t]{2}{*}{$\begin{array}{c}\text { ANTIBIÓTICOS } \\
\text { TESTADOS }\end{array}$} & \multicolumn{2}{|c|}{ A. baumannii ${ }^{I}$} & \multicolumn{2}{|c|}{${\text { E. } \text { cloaca }^{2}}^{2}$} & \multicolumn{2}{|c|}{$\begin{array}{c}\text { K. } \\
\text { pneumoniae }^{3}\end{array}$} & \multicolumn{2}{|c|}{ P. aeruginosa $a^{4}$} & \multicolumn{2}{|c|}{$\begin{array}{c}E . \\
\text { aerogenes }^{5}\end{array}$} & \multicolumn{2}{|c|}{ P. agglomerans ${ }^{6}$} \\
\hline & $\mathbf{R}^{7}$ & $\mathbf{S}^{8}$ & $\mathbf{R}$ & $\mathbf{S}$ & $\mathbf{R}$ & $\mathbf{S}$ & $\mathbf{R}$ & $\mathbf{S}$ & $\mathbf{R}$ & $\mathbf{S}$ & $\mathbf{R}$ & $\mathbf{S}$ \\
\hline Cefepime & 0 & 100 & 0 & 100 & 0 & 100 & 0 & 100 & 0 & 100 & NT & NT \\
\hline Meropenem & 0 & 100 & 0 & 100 & 25 & 75 & 0 & 100 & 0 & 100 & NT & NT \\
\hline Smt+Tmp 9 & 25 & 75 & 0 & 100 & NT & NT & 0 & 100 & NT & NT & NT & NT \\
\hline $\mathbf{A m p}+\mathbf{S u b}^{10}$ & 0 & 100 & 100 & 0 & 0 & 25 & NT & NT & 100 & 0 & NT & NT \\
\hline Piper + Tazo ${ }^{11}$ & 0 & 100 & 0 & 100 & 0 & 100 & 0 & 100 & 0 & 100 & 0 & 100 \\
\hline Ciprofloxacino & 0 & 38 & 0 & 100 & 0 & 100 & 0 & 100 & 0 & 100 & 0 & 100 \\
\hline Amicacina & 0 & 100 & 0 & 100 & 0 & 100 & 0 & 100 & 0 & 100 & NT & NT \\
\hline Gentamicina & 0 & 100 & 0 & 100 & 0 & 100 & 0 & 100 & 0 & 100 & NT & NT \\
\hline Ceftriaxona & 0 & 100 & 67 & 33 & 0 & 100 & NT & NT & 0 & 100 & NT & NT \\
\hline Ampicilina & NT & NT & 100 & 0 & 100 & 0 & NT & NT & 100 & 0 & 50 & 50 \\
\hline Cefazolina & NT & NT & 100 & 0 & NT & NT & NT & NT & NT & NT & NT & NT \\
\hline Cefoxitina & NT & NT & 100 & 0 & NT & NT & NT & NT & NT & NT & 50 & 50 \\
\hline Ertapenem & NT & NT & 0 & 100 & NT & NT & NT & NT & NT & NT & 0 & 100 \\
\hline Aztreonam & NT & NT & NT & NT & NT & NT & 0 & 100 & NT & NT & NT & NT \\
\hline Colistina & NT & NT & 0 & 100 & 0 & 100 & NT & NT & NT & NT & 0 & 100 \\
\hline
\end{tabular}

Legenda: ${ }^{1}:$ Acinetobacter baumannii; ${ }^{2}:$ Enterobacter cloacae; ${ }^{3}:$ Klebsiella pneumoniae ; ${ }^{4}:$ Pseudomonas aeruginosa; ${ }^{5}:$ Enterobacter aerogenes ; ${ }^{6}$ : Pantoa agglomerans; ${ }^{7}$ : Resistente; ${ }^{8}$ : Sensível; ${ }^{9}$ : sulfametoxazol e trimetoprima ; ${ }^{10}$ : ampicilina e sulbactam; ${ }^{11}$ : piperacilina sódica + tazobactam; NT : não testado. Fonte: Autores.

O perfil de sensibilidade e resistência dos Staphylococcus aureus (Tabela 2) foi de $76 \%$ de resistência a eritromicina, $41 \%$ a clindamicina e $6 \%$ a tetraciclina e $100 \%$ de sensibilidade para oxacilina, Smt + Tmp e Ciprofloxacino. Para os Streptococcus do grupo viridans $67 \%$ foram intermediários a eritromicina e $33 \%$ sensíveis. Enterococcus spp. e Streptococcus gallolyticus foram $100 \%$ sensíveis aos antibióticos testados. O isolado de Streptococcus vestibularis não foi testado antibiograma. 
Tabela 2. Perfil de sensibilidade e resistência das bactérias Gram-positivas encontradas nas mãos e aparelhos celulares de profissionais de saúde que trabalham e frequentam a UTI do HU-UNIVASF (EBSERH).

\begin{tabular}{|c|c|c|c|c|c|c|c|c|}
\hline \multirow[t]{2}{*}{$\begin{array}{c}\text { ANTIBIÓTICOS } \\
\text { TESTADOS } \\
\end{array}$} & \multicolumn{2}{|c|}{ S. aureus ${ }^{I}$} & \multicolumn{2}{|c|}{$\begin{array}{c}\text { Enterococcus } \\
\text { spp }\end{array}$} & \multicolumn{2}{|c|}{$\begin{array}{l}\text { S. grupo } \\
\text { viridans }\end{array}$} & \multicolumn{2}{|c|}{ S. gallolyticus ${ }^{3}$} \\
\hline & $\mathbf{R}^{5}$ & $\mathbf{S}^{6}$ & $\mathbf{R}$ & $\mathbf{S}$ & $\mathbf{R}$ & $\mathbf{S}$ & $\mathbf{R}$ & $\mathbf{S}$ \\
\hline Eritromicina & 76 & 24 & NT & NT & 0 & 33 & 0 & 100 \\
\hline Clindamicina & 41 & 59 & NT & NT & 0 & 100 & 0 & 100 \\
\hline Oxacilina & 0 & 100 & NT & NT & NT & NT & 0 & 100 \\
\hline Tetraciclina & 6 & 94 & NT & NT & NT & NT & 0 & 100 \\
\hline Vancomicina & $\mathrm{NT}$ & NT & 0 & 100 & 0 & 100 & NT & NT \\
\hline Cefepime & $\mathrm{NT}$ & NT & NT & NT & 0 & 100 & NT & NT \\
\hline Smt+Tmp ${ }^{7}$ & 0 & 100 & NT & NT & 100 & 0 & NT & NT \\
\hline Cipro $^{8}$ & 0 & 100 & NT & NT & NT & NT & 0 & 100 \\
\hline Gentamicina & NT & NT & NT & NT & NT & NT & NT & NT \\
\hline Ceftriaxona & NT & NT & NT & NT & 0 & 100 & NT & NT \\
\hline Ampicilina & $\mathrm{NT}$ & NT & 0 & 100 & NT & NT & NT & $\mathrm{NT}$ \\
\hline Cefoxitina & $\mathrm{NT}$ & NT & NT & NT & NT & NT & 0 & 100 \\
\hline
\end{tabular}

Legendas: ${ }^{1}:$ Staphylococcus aureus; ${ }^{2}:$ Enterococcus sp; ${ }^{3}:$ Streptococcus grupo viridans; ${ }^{4}$ : Streptococcus gallolyticus; ${ }^{5}$ : Resistente; ${ }^{6}$ :Sensível; ${ }^{7}$ : sulfametoxazol e trimetoprima; ${ }^{8}$ : ciprofloxacino; NT: não testado. Fonte: Autores.

\section{Discussão}

Em uma UTI o índice de IRAS é alto, há infecção cruzada de microrganismos em superfícies e equipamentos inanimados, como estetoscópios, prontuários, dentre outros, que podem ter papel significativo (Russotto et al, 2015). Em um estudo realizado por Rocha et al. (2016), 94,4\% dos equipamentos apresentavam contaminação por um ou mais microrganismo.

A principal via de infecção cruzada entre os profissionais de saúde são as mãos, sendo o Staphylococcus aureus, o Enterococcus spp. e a Klebisiella pneumoniae as bactérias mais isoladas nas mãos dos profissionais nos três grupos estudados. Resultados semelhantes foram encontrados por Custódio et al. (2009), em Goiás, ao inserir a mão dominante dos profissionais em um saco de polietileno contendo Trypticase Soy Broth, onde 40\% dos isolados foram de Staphylococcus aureus e 13\% Enterococcus spp. Higienizar as mãos é uma técnica que, na maioria das vezes, pode ser realizada de forma inadequada devido ao esquecimento de alguma das sete etapas. Segundo estudo realizado por Trannin et al (2016), a adesão é maior após a realização de procedimentos.

A região embaixo e ao redor das unhas foi o local onde mais foram encontradas bactérias possíveis causadoras de infecção hospitalar, Hardy et al. (2017) realizaram um estudo analisando o efeito das características das unhas na contagem bacteriana, onde constataram que o comprimento das unhas está associado ao aumento da carga bacteriana, sendo assim um fator de risco mesmo após a lavagem das mãos. Outro estudo realizado por MacNeil et al. (2001) analisou o uso de unhas 
artificiais, onde relatou que o uso pode aumentar o risco de transmissão de bactérias patogênicas, visto que unhas artificiais podem abrigar patógenos devido a combinação do comprimento, do uso do esmalte e do uso do material acrílico.

Quanto ao antisséptico para realizar a lavagens das mãos, em um estudo realizado por Urquiza et al. (2016) comparando a lavagem pré-cirúrgica com clorexidina $2 \%$ e antissépticos a base de iodo concluíram que as duas substâncias são eficazes na redução de microrganismos, mas a Clorexidina a $2 \%$ apresenta efeito residual. É importante ressaltar que na UTI estudada se utiliza a Clorexidina a $2 \%$, o que pode estar relacionado ao achado deste estudo em relação aos profissionais que deixam a UTI ao final do plantão apresentarem menos bactérias patogênicas.

Os aparelhos celulares também podem ser veículos de transmissão de infecção para os seus usuários, o aparecimento de bactérias possíveis causadoras de infecções hospitalares pode ter relação com a falta de higienização do aparelho e das mãos. A presença de microrganismos nos aparelhos celulares pode acarretar IRA devido à transmissão de bactérias na realização de procedimentos sem a realização de medidas de prevenção (Caveião et al., 2014). O estudo realizado por Reis et al. (2015), mostrou uma contaminação de Staphylococcus aureus, incluindo MRSA, em todos os aparelhos celulares analisados de profissionais que trabalham em uma UTI, destacando que todos os profissionais utilizam aparelho celular no setor, mas apenas $24 \%$ realizam a desinfecção.

O Staphylococcus aureus foi o microrganismo presente nos três grupos estudados, tanto nas mãos como nos aparelhos celulares. É um importante patógeno humano que causa uma gama de infecções clínicas, como infecções da corrente sanguínea e infecções respiratórias. O S. aureus resistente a oxacilina (MRSA) pode causar infecções hospitalares e grandes infecções epidérmicas de difícil tratamento e esta resistência é conferida pela expressão do gene mecA. A Vancomicina é a droga de escolha para o tratamento da MRSA, porém deve ser reservada para casos mais graves, bem como a linezolida droga que tem se mostrado superior em infecções graves, principalmente em pacientes em UTI (Agência Nacional de Vigilância Sanitária, 2011; Corrêa et al., 2018; Hussain, 2019).

No presente estudo, o perfil de resistência para o S. aureus foi de $76 \%$ de resistência a eritromicina e $41 \%$ de resistência a clindamicina, múltiplos mecanismos podem conferir resistência aos antimicrobianos macrolídeos, lincosamidas e estreptogramina B (MLS ${ }_{b}$ ), o mecanismo de modificação no alvo de ligação no ribossomo (fenótipo MLS) pode ser induzível (MLS $\mathrm{b}$ i) ou constitutiva (MLS $\mathrm{b}$ ), o fenótipo induzível pode limitar o uso da clindamicina. Recomenda-se a realização do teste de indução realizado em laboratório e liberado no laudo e o monitoramento para indicar a possibilidade de falha que pode existir no uso da clindamicina como tratamento (Amorim et al., 2009; Merino-Díaz et al., 2007).

Outro microrganismo frequente em todos os grupos foi o Enterococcus spp. Em um estudo realizado por Ram e Sharma (2015), a bactéria presente no trato gastrointenstinal e no geniturinário foi a mais encontrada em telefones celulares de profissionais da saúde, resultado semelhante ao encontrado neste estudo. Apesar dos isolados apresentarem sensibilidade a vancomicina, a prevalência de Enterococcus spp. resistente a vancomicina (VRE) é comum nas UTIs, dentre os mecanismos de resistência está a modificação dos sítios de ação dos antibióticos, sendo os genótipos vanA e vanB os mais comuns. Na metanálise realizada por Caicedo-Ochoa et al. (2017), foi constatado que no tratamento para VRE, em relação a mortalidade não há diferença entre a daptomicina e a linezolida, porém a cura microbiológica é mais rápida com o uso da daptomicina (Agência Nacional de Vigilância Sanitária, 2011; Figueredo et al., 2017).

Os resultados encontrados para Klebsiella pneumoniae resistente ao meropenem nas mãos de profissionais que deixam o plantão é preocupante. A K. pneumoniae é uma das principais causas de infecções em paciente internados em terapia intensiva e sua resistência aos carbapenêmicos envolve múltiplos mecanismos, as enzimas Amp C e Beta-lactamases de espectro ampliado (ESBL) são mais propensas a contribuir na suscetibilidade aos carbapenêmicos, outro mecanismo enzimatico é o mediado pelo gene blaKPC. Dessa forma, os mecanismos de resistência dificultam o tratamento para este tipo de infecção e alertam para a necessidade da adoção de medidas que controlem a disseminação de bactérias multiressistentes, 
pois bactérias produtoras de carbapenemase são capazes de degradar todos os antibioticos betalactâmicos, penicilinas e cefalosporinas, o que causa grande preocupação no ambiente hospitalar, pois as opções terapêuticas diminuem (Pitout, 2015; Zanol, 2016; Restrepo, 2015).

O Acinetobacter baumannii foi o microrganismo prevalente nas mãos dos profissionais que entram na UTI para realizar alguma atividade. Este microrganismo pode causar diferentes infecções, na maioria das vezes infecções do trato respiratório e no estudo apresentou $25 \%$ de resistência a ampicilina + sulbactam que é uma penicilina agrupada a um inibidor da betalactamase. Dentre os principais mecanismos de resistência estão às enzimas de inativação antimicrobiana como as betalactamases, $\mathrm{N}$-acetiltransferases, O-nucleotidiltransferases e O-fosfotransferasese. Quanto ao tratamento, os carbapenêmicos são as drogas de escolha para o tratamento de infecções graves por A. baumannii e quando esses são resistentes como última linha de tratamento se utiliza a colistina e no Brasil a Polimixina B (Doi, 2015; Buenahora et al., 2016).

Os números relacionados às IRAS continuam sendo um problema preocupante no ambiente hospitalar, principalmente em ambientes críticos como a Unidade de Terapia Intensiva. Pode-se observar que os profissionais de saúde que trabalham e frequentam a UTI do HU-UNIVASF possuem nos aparelhos celulares, assim como nas mãos, uma microbiota transitória com bactérias multirresistentes que poderão causar infecções hospitalares. A melhor forma de prevenir infecções cruzadas é a higienização das mãos. Para isso é necessário que ocorra uma conscientização dos profissionais para a correta lavagem das mãos antes e após os procedimentos. Em relação aos aparelhos celulares recomenda-se a higienização com álcool a 70\% e evitar ao máximo o uso do celular antes e após a realização de algum procedimento.

\section{Conclusão}

Os profissionais que atuam na UTI do HU-UNIVASF e aqueles que entram para realizar alguma atividade possuem em suas mãos e aparelhos celulares bactérias multirresistentes causadoras de infecções hospitalares que poderão causar infecções cruzadas.

Assim, é de suma importância que haja uma educação continuada para a higienização correta das mãos, pois esse é o método mais eficaz para a diminuição de infecções cruzadas. Sugere-se ainda, para melhor conhecimento sobre o tema, a ampliação deste estudo para a avaliação de outras alas hospitalares; possibilitando, dessa forma, um melhor conhecimento do desenvolvimento das IRAS nos serviços de saúde.

\section{Referências}

Agência Nacional de Vigilância Sanitária (2011). Investigação e controle de bactérias multirresistentes.

Agência Nacional de Vigilância Sanitária (2017). Medidas De Prevenção De Infecção Relacionada À Assistência À Saúde.

Araújo, D. D. D., Silva Junior, R. F. D., Alves, E. C. S., Gusmão, R. O. M., \& Mota, É. C. (2016). A importância da higienização das mãos no controle das infecções em serviços de saúde. Rev. enferm. UFPE on line, 4880-4884.

Caicedo-Ochoa, E. Y., Urrutia-Gómez, J. A., Fernández-Niño, D. S., Guío-Guerra, S. A., \& Méndez-Fandiño, Y. R. (2017). Tratamiento de la bacteriemia por enterococo resistente a vancomicina con daptomicina versus linezolid: revisión sistemática y metanálisis. Iatreia, 30(1), 5-20.

Cardoso, A. M., \& Reis, C. (2016). Contaminação de superfícies inanimadas de UTI por bactérias Gram negativas multirresistentes em hospital universitário de Goiânia, GO. RBAC, 48(3 supl 1), 59-65.

Caveião, C., Novello, N., Sales, W. B., Visentin, A., Brey, C., \& de Oliveira, V. B. C. A. (2014). SWAB de vigilância em aparelhos de celulares em hospital de Curitiba-PR: relato de experiência. Cadernos da Escola de Saúde, 2(12).

Centers for Disease Control and Prevention (2019). Healthcare-associated infections. https://www.cdc.gov/hai/index.html

Corrêa, R. D. A., Costa, A. N., Lundgren, F., Michelin, L., Figueiredo, M. R., Holanda, M., \& Pereira, M. C. (2018). Recomendações para o manejo da pneumonia adquirida na comunidade 2018. Jornal Brasileiro de Pneumologia, 44(5), 405-423. 
Cunha, E. B. (2017). Aspectos relevantes da prevenção e controle de infecções hospitalares. Saber Científico 6, 64 - 77.

Custódio, J., Alves, J. F., Silva, F. M., von Dolinger, E. J. O., dos Santos, J. G. S., \& de Brito, D. V. D. (2012). Avaliação microbiológica das mãos de profissionais da saúde de um hospital particular de Itumbiara, Goiás. Revista de Ciências Médicas, 18(1).

de Aguiar Portela, D., Mouta, A. A. N., Alves, A. R. R., de Almeida, F. C. R., da Silva, A. C. B., Lopes, P. F., ... \& Beltrão, R. P. L. (2020). A importância da higienização das mãos nas unidades de terapia intensiva: os perigos das infecções relacionadas à assistência à saúde. Revista Eletrônica Acervo Saúde, 12(9), e3854-e3854.

de Carvalho Urquiza, M., dos Anjos, A. D. S., Ribeiro, A. C. B., da Costa Borba, M. S., de Carvalho Filho, D. U., \& Lago, E. C. (2016). Comparação da eficácia e efeito residual de duas técnicas de antissepsia pré-operatória das mãos com duas substâncias antissépticas. Revista Interdisciplinar, 9(3), 112-120.

de Sousa, M. A. S., Nascimento, G. C., Bim, F. L., de Oliveira, L. B., \& da Silva Oliveira, A. D. (2017). Infecções hospitalares relacionadas a procedimentos invasivos em unidades de terapia intensiva: revisão integrativa. Revista Prevenção de Infecção e Saúde, 3(3).

Doi, Y., Murray, G. L., \& Peleg, A. Y. (2015, February). Acinetobacter baumannii: evolution of antimicrobial resistance-treatment options. In Seminars in respiratory and critical care medicine $(36,85)$. NIH Public Access.

dos Reis, L. E., Silva, W., Carvalho, E. V., da Costa Filho, A., \& Braz, M. R. (2017). Contaminação de telefones celulares da equipe multiprofissional em uma unidade de terapia intensiva. Revista Saber Digital, $8(01), 68-83$.

dos Santos, A. B., Silva, K. S. B., Santana, M. M. R., Marques, M. W., \& Naue, C. R. (2020). Perfil bacteriano das superfícies e equipamentos do Bloco Cirúrgico de um Hospital Universitário. VITTALLE-Revista de Ciências da Saúde, 32(1), 101-107.

Dresch, F., Birkheuer, C. F., Rampel, C., \& Maciel, M. J. (2018). Contaminação de superfícies localizadas em unidades de terapia intensiva e salas de cirurgia: uma revisão sistemática da literatura. Rev de Epidemiol e Control Infec, 8(1), 85-91.

Figueredo, R. A. M., Oliveira, J. T., Silva, A. M. T. C., \& Ataides, F. S. (2017). Enterococcus resistente à vancomicina: uma preocupação em expansão no ambiente hospitalar. Journal of Infection Control, 6(1), 11-15.

Fracarolli, I. F. L., Oliveira, S. A. D., \& Marziale, M. H. P. (2017). Colonização bacteriana e resistência antimicrobiana em trabalhadores de saúde: revisão integrativa. Acta Paulista de Enfermagem, 30(6), 651-657.

Hardy, J. M., Owen, T. J., Martinez, S. A., Jones, L. P., \& Davis, M. A. (2017). The effect of nail characteristics on surface bacterial counts of surgical personnel before and after scrubbing. Veterinary Surgery, 46(7), 952-961.Van Hoecke, F. R. E. D. E. R. I. K., Deloof, N., \& Claeys, G. (2011). Performance evaluation of a modified chromogenic medium, ChromID MRSA New, for the detection of methicillin-resistant Staphylococcus aureus from clinical specimens. European journal of clinical microbiology \& infectious diseases, 30(12), 1595-1598.

Hussain, M. S., Naqvi, A., \& Sharaz, M. (2019). Methicillin Resistant Staphylococcus Aureus (Mrsa). The Professional Medical Journal, $26(01)$, $122-127$.

Inoue, K. C., \& Matsuda, L. M. (2010). Dimensionamento de pessoal de enfermagem em Unidade de Terapia Intensiva para adultos. Acta Paulista de Enfermagem, 23(3), 379-384.

McNeil, S. A., Foster, C. L., Hedderwick, S. A., \& Kauffman, C. A. (2001). Effect of hand cleansing with antimicrobial soap or alcohol-based gel on microbial colonization of artificial fingernails worn by health care workers. Clinical Infectious Diseases, 32(3), 367-372.

Menezes, R. M., Cardoso, V., Hoehr, C. F., Bulle, D., Burgos, M. S., Benitez, L. B., \& Renner, J. D. P. (2016). Avaliação microbiológica da antissepsia préoperatória das mãos de profissionais de enfermagem de um centro cirúrgico. Revista de Epidemiologia e Controle de Infecção, 1(1), $178-191$.

Mourão, M. D. F. R., \& Chagas, D. R. (2020). Ações de prevenção e controle de infecção em hospitais. Brazilian Journal of Development, 6(6), $38406-38417$. Paula, A. O., Salge, A. K. M., \& Palos, M. A. P. (2017). Infecções relacionadas à assistência em saúde em unidades de terapia intensiva neonatal: uma revisão integrativa. Enfermería Global, 16(1), 508-536.

Peirano, G., Seki, L. M., Val Passos, V. L., Pinto, M. C. F., Guerra, L. R., \& Asensi, M. D. (2009). Carbapenem-hydrolysing $\beta$-lactamase KPC-2 in Klebsiella pneumoniae isolated in Rio de Janeiro, Brazil. Journal of Antimicrobial Chemotherapy, 63(2), 265-268.

Pereira, A.S.; Shitsuka, D.M.; Parreira, F.J. \& Shitsuka, R. (2018). Metodologia da pesquisa científica. UFSM.

Pitout, J. D., Nordmann, P., \& Poirel, L. (2015). Carbapenemase-producing Klebsiella pneumoniae, a key pathogen set for global nosocomial dominance. Antimicrobial agents and chemotherapy, 59(10), 5873-5884.

Ram, T., \& Sharma, M. (2015). Prevalence and Antibiotic Sensitivity of Enterococcus sp. from Mobile Phones of Doctors and Nurses. Journal of Pure and Applied Science \& Technology, 5(2), 73-80.

Restrepo, A. D. D. C. F., \& Arias, C. A. A. (2015). Resistencia a los antibióticos beta-lactámicos Carbapenems mediada por el gen blaKPC en Klebsiella pneumoniae. Revista de Investigación Agraria y Ambiental, 6(2), 109-118.

Rocha, I. V., Ferraz, P. D. M., Farias, T. G. S. D., \& Oliveira, S. R. D. (2015). Resistência de bactérias isoladas em equipamentos em unidade de terapia intensiva. Acta Paulista de Enfermagem, 28(5), 433-439.

Rodriguez Buenahora, R. D., Bustillo Zarate, D. E., Caicedo Sanchez, D. C., Cadena Sarmiento, D. C., \& Castellanos Gomez, C. (2016). Acinetobacter baumannii: patógeno multirresistente emergente. Medicas UIS, 29(2), 113-135.

Rosa, J. O., Moura, J. P., Palos, M. A. P., Gir, E., Reis, C., Kipnis, A., \& Pimenta, F. C. (2009). Detecção do gene mecA em estafilococos coagulase negativa resistentes à oxacilina isolados da saliva de profissionais da enfermagem. Revista da Sociedade Brasileira de Medicina Tropical, 42(4), 398-403. 
Research, Society and Development, v. 10, n. 9, e5510917688, 2021

(CC BY 4.0) | ISSN 2525-3409 | DOI: http://dx.doi.org/10.33448/rsd-v10i9.17688

Russotto, V., Cortegiani, A., Raineri, S. M., \& Giarratano, A. (2015). Bacterial contamination of inanimate surfaces and equipment in the intensive care unit. Journal of intensive care, 3(1), 1-8.

Serra Valdés, M. Á. (2017). La resistencia microbiana en el contexto actual y la importancia del conocimiento y aplicación en la política antimicrobiana. Revista Habanera de Ciencias Médicas, 16(3), 402-419.

Trannin, K. P. P., Campanharo, C. R. V., Lopes, M. C. B. T., Okuno, M. F. P., \& Batista, R. E. A. (2016). Adesão à higiene das mãos: intervenção e avaliação. Cogitare Enfermagem, 21(2).

World Health Organization. (2016). Guidelines on core components of infection prevention and control programmes at the national and acute health care facility level. World Health Organization.

Zanol, F. M. (2016). Klebsiella pneumoniae carbapenemase (KPC): um mecanismo de resistência emergente. Suplemento Especial De Microbiologia E Micologia, 48(3 supl 1), 4-9. 